\title{
Application of Qualitative Information System in Assessing Household Water, Sanitation and Hygiene Behaviors in Rural Bangladesh: A Cross-sectional Comparative Study
}

\author{
Tahera Akter*, Mahmudur Rahman, Mahfuzar Rahman \\ BRAC Research and Evaluation Division, BRAC Centre, Dhaka, Bangladesh \\ Email address: \\ tahera13b@gmail.com (T. Akter), mahmudur.rahman70@gmail.com (M. Rahman), mahfuzar.rahman@brac.net (M. Rahman) \\ ${ }^{*}$ Corresponding author
}

\section{To cite this article:}

Tahera Akter, Mahmudur Rahman, Mahfuzar Rahman. Application of Qualitative Information System in Assessing Household Water, Sanitation and Hygiene Behaviors in Rural Bangladesh: A Cross-sectional Comparative Study. Journal of Health and Environmental Research. Vol. 5, No. 3, 2019, pp. 78-86. doi: 10.11648/j.jher.20190503.12

Received: January 27, 2019; Accepted: September 6, 2019; Published: September 24, 2019

\begin{abstract}
Ensuring the condition of water, and sanitation facilities is the early step to behavior change. However, mere provision of facilities does not ensure the desired behavioral change, thus health benefits. To improve health of the rural poor, the water, sanitation and hygiene (WASH) program of Bangladesh Rural Advancement Committee (BRAC) has been working in rural sub-districts since 2006. The main objective of the present study is to assess the status and quality of hygiene practice of some WASH indicators by the application of qualitative information system (QIS). This was a cross-sectional comparative study between intervention and comparison areas. A multi-stage random sampling technique was used to select study samples, where each sub-district was considered as a cluster. Total 880 households were selected randomly from 22 upazilas for data collection. Thirty-six interviewers grouped into twelve were trained intensively on data collection tools and techniques. Both observed (spot check) and self-reported data were collected using structured questionnaire to assess the status and quality of WASH practices. The scaling principles of qualitative information system (QIS) were applied to analyze data on WASH behaviors. The uniqueness of QIS method is that WASH practices are monitored and measured by collecting quantitative information on qualitative aspects. More households in intervention areas than comparison areas scored above benchmark in using arsenic free and protected drinking water source (69\%. vs. 53\%). There was no significant difference between the areas in terms of installing latrine within 12 steps of tubewell. Higher proportion of households in intervention areas had clean and two-pit latrines than comparison areas (61\% vs. $34 \%)$. Drinking water was collected and stored safely from the safe source by $65 \%$ households in intervention areas higher than the comparison areas $(65 \%$ vs. $52 \%)$. Unhygienic sanitation practices (e.g., open defecation, latrine without ring-slab, water seal) were found higher among the households in comparison areas than intervention areas ( $56 \%$ vs. $22 \%$ ). More households in intervention than comparison areas reached at above benchmark in maintaining hygiene. However concern over unhygienic sanitation behaviors and relative distance between latrine and tubewell is required for enabling environment thus public health.
\end{abstract}

Keywords: WASH Behavior, Qualitative Information System, BRAC

\section{Introduction}

Sustainable Development Goal (SDG) 6 depicts sustainable management of water and sanitation for all by 2030. Lack of access to safe water and sanitation facilities still remains a global concern. According to the SDG progress report (2018) [1], 3 in 10 people and 6 in 10 people lack access to safely managed drinking water and sanitation facilities, respectively. The situation remained same while recording the MDG progress report. Ensuring environmental sustainability, one of the MDG goals set for 2015 was a vital and crucial clog in the wheel of achieving success in covering the eight MDG goals set for 2015. It is often reported that the proportion of households with access to safe drinking water is on track to meet the Millennium Development Goals (MDGs), while the proportion of those 
with access to proper sanitation is often said to be "lagging behind water supply" [2]. According to JMP report (2013), drinking water coverage in 2011 was $89 \%$ which stood ahead of the MDG drinking water target. On the other hand, sanitation coverage in 2011 was only $64 \%$ which remained behind the MDG sanitation target of $75 \%$ [3]. Thus, more than 2.6 billion people today suffer from a basic lack of proper sanitation facilities with nearly two-thirds living in Asia and sub Saharan African region [4]. Globally, a look at the facts indicate that between 1990 and 2012, 2.3 billion people gained vital access to improved drinking water conditions, but still more than 2.5 billion remain untouched and without proper access to safe drinking water options. While progress has been made, a lot more improving strides need to be taken since still now more than 1 billion people practice open defecation worldwide, 748 million people have poor access to drinking water and millions still have no access to a proper soap and needed water supply to wash their hands [5].

Earlier the Government of Bangladesh had set a national target of $100 \%$ sanitation coverage by 2013 . The main requirements of achieving that includes no open defecation, hygiene latrines available for all and use the facilities by all, improved hygienic practice and proper maintenance of hygienic latrines through continual usage by all. This is a step towards achieving the MDGs set for 2015. Though Bangladesh has already made significant strides, the country is primarily at cross roads and substantially is lagging behind in implementing measures to improve sanitation and hygiene practices in both rural (31\%) and urban (71\%) areas and help reduce the knowledge and practice gap [2]. Inclusion of people from all strata of society has been emphasized in sanitation campaign to improve the situation. However, to bring the poor and ultra-poor into $100 \%$ sanitation coverage remains a challenge. The BRAC WASH program has been working on this challenging area in order to achieve the goal and to support the government in its implementation efforts. The BRAC WASH program primarily operates through the Village Wash Committees (VWCs). The VWCs through its 11 member stakeholder groups arouses various WASH related issues facing a certain village and helps aware the local BRAC office of those needs. Some of the major tasks of the VWC are to make arrangements to install new sanitary latrines, convert unhygienic latrines to sanitary ones by changing water seals, installing tubewells and arranging educational activities to increase awareness about hygiene behavior.

The Research and Evaluation Division (RED) of BRAC conducted a number of studies in WASH-I upazilas and identified some challenging areas towards improving WASH behaviors such as breaking the water seals [6], gap between knowledge on and practice of hygiene [7], water shortage [8] and difficulties in carrying water [9], water safety practices considering distance between latrine and tubewell [8], etc. Rural households also tend to slip back into old, unsanitary habits very quickly if new latrines become blocked, broken, or smell bad and if timely guidance and encouragement are not provided [10]. To convert hygiene knowledge into practice and practice into habit was stressed in phase-I research finding which was also considered to be a major challenge for the succeeding intervention phases of the WASH programme. Therefore, the number of core messages focusing on WASH behaviors was reduced from 19 to 7 in the next phase of the programme. The seven key WASH behaviors are: 1) use of safe and protected drinking water source; 2) hygienic management of drinking water from source to point-of-use; 3) condition of hygienic latrine; 4) use of latrine by different household members; 5) consistency of latrine use at day/night time and across seasons; 6) sludge management when latrine pit is full; 7) hand washing provision near the latrine after defecation.

The BRAC WASH program regular monitors its output through management information system (MIS) data and determines the coverage quantitatively. However, the quality of practice (i.e. WASH outcomes) is seldom measured through an improved method. Considering methodological rigor, the program measured some indicators on core WASH messages following the scaling principles of qualitative information system (QIS). This system is developed jointly by the BRAC WASH Program and International Water and Sanitation Centre (IRC). This method has become stronger after several rigorous testing in the field. The power of this method is that it monitors WASH outcomes by collecting quantitative data on qualitative aspects. In this method information on each parameter is collected qualitatively at first and then quantified in a progressive scale of 0 to 4 starting from the very basic to the advanced level. Each forwarding step of the system describes a situation in order to check the quality of hygiene practice. Measuring some parameters through this information system gives an insight to behavior change of households. The present study aims to assess the status of some of the key WASH behaviors by using qualitative information system.

\section{Methods}

\subsection{Study Design and Area}

This was a cross-sectional comparative study between intervention and comparison areas. The status of WASH indicators on behavior change was compared between the areas. In such context, a total of 22 upazilas spread over the country including intervention (BRAC WASH) and comparison (non-BRAC WASH) areas were selected (Figure 1). Those upazilas were taken up as comparison where BRAC WASH interventions are not present, but other NGOs may have kind of WASH activities.

\subsection{Sample Size and Sampling}

A multi-stage random sampling was used to select study samples, where each upazila was considered as a cluster. Assuming a $50 \%$ increase in the prevalence of key WASH indicators from its previous status, $80 \%$ power, $5 \%$ significance level and a design effect of 1.5 times, the total 
sample size was estimated at 880 households. The estimated sample was then disaggregated at upazila level for getting a general picture of WASH behaviors among the households. Twenty-two upazilas (about five-percent of the total upazila) comprised of 11 BRAC WASH and 11 non-BRAC WASH upazilas were selected systematically for data collection. From each upazila, 2 unions, from each union one village and from each village 20 households were selected. A total of 440 households from intervention and 440 households from comparison upazilas were selected using systematic random sampling (Figure 1). To avoid the systematic bias in each stage, the interval sampling technique was used to select upazila, union and households.

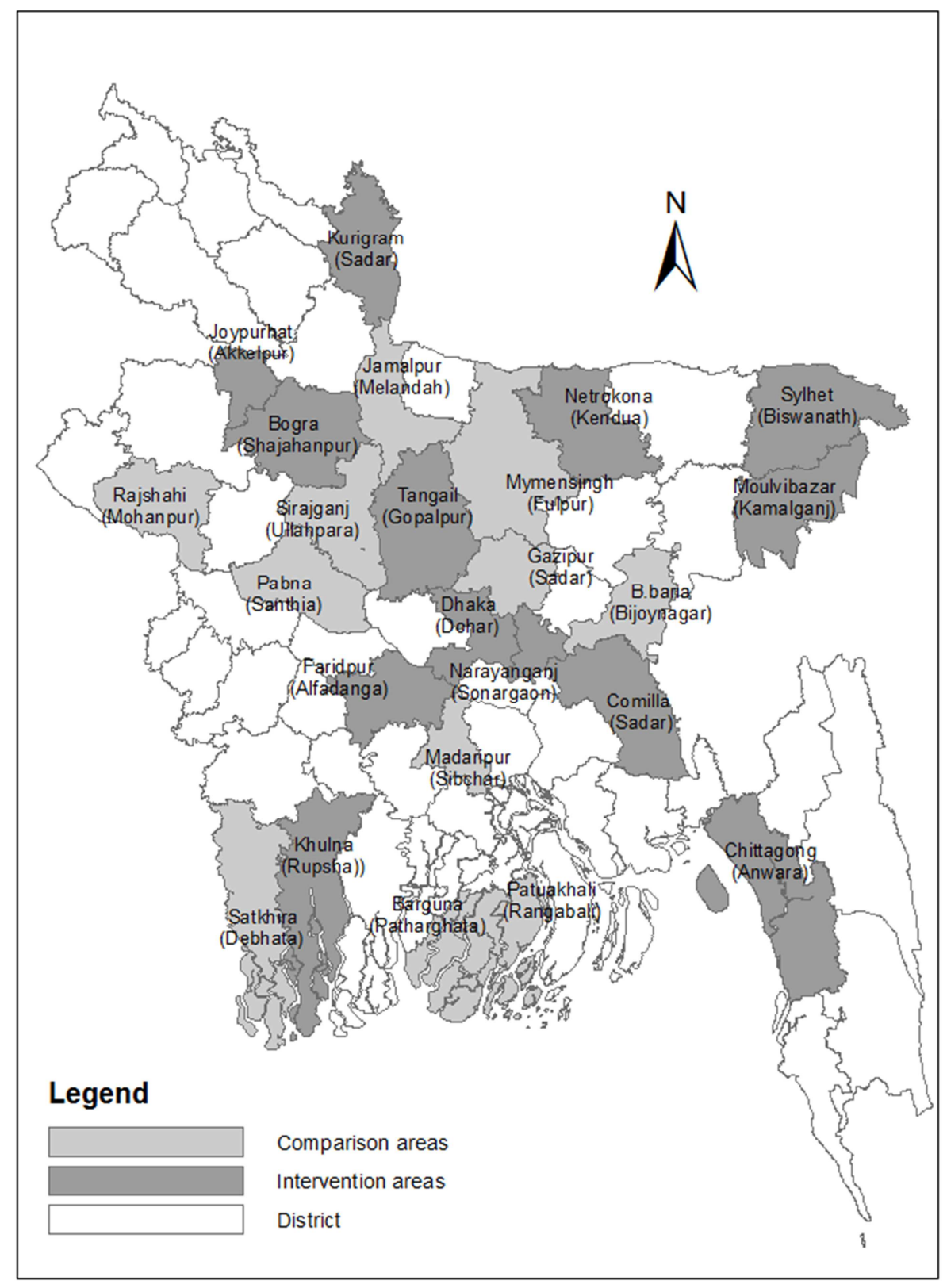

Figure 1. Study upazila.

\subsection{Data Management and Quality Control}

Trained field interviewers collected data from households through face-to-face interviews using a pre-tested structured questionnaire. In all, 33 interviewers were employed, trained, and divided into 11 groups for data collection in the field. Each group had 3 members including one supervisor. A field test was carried out in Singair upazila, Manikganj district close to Dhaka before the actual field survey. The collected data were consisted of socio-demographic, economic, and behavioral information of study samples. Data on source of drinking water, hygienic management of drinking water, condition of hygienic latrines and hand washing provision near the latrine after defecation were collected through spot observation. Some proxy indicators such as availability of soap and water near the latrine was checked on the spot to measure the status of hand washing provision after defecation. The information related to WASH indicators was 
collected by following the scaling principles of QIS included: 1) 0 score if no characteristics of condition/practice present; 2) score 1 if primary characteristics present; 3) score 2 if primary and secondary characteristics present which indicate benchmark condition or minimum condition that the program wants to achieve program-wide; 4) score 3 and 4 represent the next two levels where score 4 represents the ideal condition meaning all characteristics are present [11].

The interviewers were trained intensively on data collection tools and techniques for 3 days. A training manual with instruction of data collection procedure was developed and used as a reference in the field. An adult female member capable of providing household level information was interviewed using the pre-tested questionnaire. Female respondents are chosen since they are usually responsible for collecting and storing water and maintenance of the latrines at households. To ensure completeness and consistency, the interviewers were instructed to cross-check each other's questionnaire. The field managers and researchers randomly selected some completed questionnaires to check the quality of collected data. If any inconsistency was found, the respondent was revisited to make necessary corrections with the data. The completed data was coded, entered and cleaned for completeness and consistency by data management unit of Research and Evaluation Division.

\subsection{Statistical Analysis}

An index of four variables was developed: 1) Source of drinking water; 2) Drinking water management; 3) Characteristics of hygienic latrine; and 4) Hand washing provision after defecation. Each of the variables had 5 category points whereas 0 and 1 meant below benchmark; 2 meant benchmark; and 3 and 4 meant above benchmark (Table 1). The index was constructed using the four variables via principal components analysis.

Table 1. WASH behaviors and score characteristics.

\begin{tabular}{|c|c|c|c|c|c|}
\hline \multirow{3}{*}{$\begin{array}{l}\text { WASH } \\
\text { Behavior }\end{array}$} & \multicolumn{5}{|c|}{ Score characteristics } \\
\hline & \multicolumn{2}{|l|}{ Below benchmark } & \multirow{2}{*}{$\begin{array}{l}\text { At benchmark } \\
2\end{array}$} & \multicolumn{2}{|l|}{ Above benchmark } \\
\hline & $\mathbf{0}$ & 1 & & 3 & 4 \\
\hline $\begin{array}{l}\text { Source of } \\
\text { drinking } \\
\text { water }\end{array}$ & $\begin{array}{l}\text { Unsafe (arsenic } \\
\text { affected, not } \\
\text { boiling of water } \\
\text { collected from } \\
\text { open source) }\end{array}$ & $\begin{array}{l}\text { (1) Arsenic free } \\
\text { water source } \\
\text { (tubewell), filtered } \\
\text { or boiled surface } \\
\text { water }\end{array}$ & $\begin{array}{l}\text { BENCHMARK: }(1) \\
\text { Arsenic free water } \\
\text { source (tubewell), } \\
\text { filtered or boiled } \\
\text { surface water }+(2) \text { no } \\
\text { stagnant water around } \\
\text { the tubewell }\end{array}$ & $\begin{array}{l}\text { (1) Arsenic free water } \\
\text { source (tubewell), filtered } \\
\text { or boiled surface water + } \\
\text { (2) no stagnant water } \\
\text { around the tubewell + (3) } \\
\text { brick-built and crackles } \\
\text { tubewell platform }\end{array}$ & $\begin{array}{l}\text { IDEAL: (1) Arsenic free water } \\
\text { source (tubewell), filtered or boiled } \\
\text { surface water }+(2) \text { no stagnant } \\
\text { water around the tubewell }+(3) \\
\text { brick-built and crackles tubewell } \\
\text { platform }+(4) \text { no latrine within } 12 \\
\text { steps }\end{array}$ \\
\hline $\begin{array}{l}\text { Drinking } \\
\text { water } \\
\text { management }\end{array}$ & $\begin{array}{l}\text { Unsafe (arsenic } \\
\text { affected, not } \\
\text { boiling of water } \\
\text { collected from } \\
\text { open source) }\end{array}$ & $\begin{array}{l}\text { (1) Arsenic free } \\
\text { water source } \\
\text { (tubewell), filtered } \\
\text { or boiled surface } \\
\text { water }\end{array}$ & $\begin{array}{l}\text { BENCHMARK: (1) } \\
\text { Arsenic free water } \\
\text { source (tubewell), } \\
\text { filtered or boiled } \\
\text { surface water }+(2) \\
\text { safe collection }\end{array}$ & $\begin{array}{l}\text { 1) Arsenic free water } \\
\text { source (tubewell), filtered } \\
\text { or boiled surface water }+ \\
\text { (2) safe collection }+(3) \\
\text { brick-built and crackles } \\
\text { tubewell platform }\end{array}$ & $\begin{array}{l}\text { IDEAL: (1) Arsenic free water } \\
\text { source (tubewell), filtered or boiled } \\
\text { surface water }+(2) \text { safe collection }+ \\
\text { (3) brick-built and crackles tubewell } \\
\text { platform }+(4) \text { safe storage }\end{array}$ \\
\hline $\begin{array}{l}\text { Characteristic } \\
\mathrm{s} \text { of hygienic } \\
\text { latrine }\end{array}$ & $\begin{array}{l}\text { open defecation or } \\
\text { latrine without } \\
\text { ring and slab }\end{array}$ & $\begin{array}{l}\text { Latrine with (1) } \\
\text { Ring and slab, but } \\
\text { no water seal }\end{array}$ & $\begin{array}{l}\text { BENCHMARK: } \\
\text { Latrine with (1) ring } \\
\text { and slab }+(2) \text { active } \\
\text { water seal }\end{array}$ & $\begin{array}{l}\text { Latrine with (1) ring and } \\
\text { slab }+(2) \text { active water seal } \\
+(3) \text { no feces visible in } \\
\text { pan, slab, water seal and } \\
\text { walls }\end{array}$ & $\begin{array}{l}\text { IDEAL: Latrine with (1) Ring and } \\
\text { slab }+(2) \text { active water seal }+(3) \text { no } \\
\text { feces visible in pan, slab, water seal } \\
\text { and walls }+(4) \text { latrine with two pits }\end{array}$ \\
\hline $\begin{array}{l}\text { Hand washing } \\
\text { provision } \\
\text { after } \\
\text { defecation }\end{array}$ & $\begin{array}{l}\text { No provision of } \\
\text { water for hand } \\
\text { washing carried or } \\
\text { available in/near } \\
\text { the latrine }\end{array}$ & $\begin{array}{l}\text { (1) Enough water } \\
\text { to wash hands } \\
\text { carried or } \\
\text { available in/near } \\
\text { the latrine }\end{array}$ & $\begin{array}{l}\text { BENCHMARK: }(1) \\
\text { Enough water to wash } \\
\text { hands carried or } \\
\text { available in/near the } \\
\text { latrine }+(2) \text { Soap/soap } \\
\text { solution in bottle at } \\
\text { latrine }\end{array}$ & $\begin{array}{l}\text { (1) Enough water to wash } \\
\text { hands carried or available } \\
\text { in/near the latrine }+(2) \\
\text { Soap/soap solution in } \\
\text { bottle at latrine+ (3) Water } \\
\text { from safe source is used } \\
\text { for hand washing }\end{array}$ & $\begin{array}{l}\text { IDEAL: (1) Enough water to wash } \\
\text { hands carried or available in/near } \\
\text { the latrine }+(2) \text { Soap/soap solution } \\
\text { in bottle at latrine+ }(3) \text { Water from } \\
\text { safe source is used for hand } \\
\text { washing +(4) Special hand washing } \\
\text { station }\end{array}$ \\
\hline
\end{tabular}

First step, categorical variables were transformed into separate dichotomous (0-1) indicators. The second step combined the factor scores through a regression on the common factor scores. This two-step procedure permitted greater adaptability of the hygiene index. The resulted composite hygiene index had a mean of zero and a standard deviation of one. Once the index was computed, hygiene quantiles (from highest to lowest) were obtained by assigning score to each of the household, and ranking each household by the score, and then dividing the ranking into five equal categories (as there were five categories), each comprising 20 percent of the population. Another variable combining first 3 categories as 'benchmark or above' and last two categories as 'below benchmark' was generated.

In an analysis of the common outcome (over 50\% prevalence), for instance hygiene practice in this study, Poisson regression was applied whereas incidence rate ratio (IRR) estimated risk ratios (RRs) and 95\% confidence intervals (CIs). The interpretation of odds ratio (OR) of logistic regression was not considered appropriate because OR overstated RR [12]. Log-binomial could not be used because of the limitation of convergence [13]. A database of dichotomous variables was created to simulate the outcome 'hygiene practice' related to several independent variables, such as exposure to education, NGOs, media (radio, TV etc.) at home, etc. In addition to these exposure factors, the 
household's economic status (wealth index) and different ecological zone were also included in the model. A score of ' 1 ' was assigned to the groups exposed to the predictor factors, while the non-exposed groups were denoted as ' 0 '. Statistical analysis was performed in STATA software. The results were expressed as IRR's (adjusted and unadjusted) with $95 \%$ confidence Intervals (CIs).

\subsection{Ethical Issues}

Ethical approval was obtained from James P. Grant School of Public Health, BRAC University. Informed verbal consent was taken from each respondent before data collection. Respondents were assured that they could withdraw from the interview at any time and their refusal would not affect receiving any service from BRAC in future. Moreover, respondents' identity were kept confidential and not mentioned while reporting. Confidentiality was maintained in data handling, as dataset was stored safely and only researchers could access it.

\section{Results}

\subsection{Background Characteristics of the Study Samples}

The demographic and socioeconomic profile of study samples depicted that the average age of household head was 47 years. Of them, 58\% had attended school at some point. More than a third of them (34\%) were involved in agricultural work, followed by $20 \%$ in labor oriented occupation, $17 \%$ in business, $9 \%$ in service, and $6 \%$ in household chores. The total households were divided into three broad economic groups based on land ownership and we found $28 \%$ ultra-poor, $43 \%$ poor and $29 \%$ non-poor households. Over half of the households (55\%) were not affiliated with any NGO. Less than half of them (47\%) had access to media (e.g. television) at home, while only $4 \%$ had radio at home. In addition, more than $76 \%$ households' main living rooms were kutcha, i.e. made of temporary materials such as bamboo, jute sticks, leaves, wood, mud, tin, etc.

\subsection{Hygiene Behavior}

\subsubsection{Safe and Protected Drinking Water Source}

The primary characteristic attributed to the safe and protected drinking water source was arsenic free tubewell water, and filtered or boiled surface water. Other traits included no stagnant water around the tubewell, brick-built and crackles tubewell platform, and no latrine within 12 steps of the tubewell. A higher proportion of households (69\%) in intervention areas scored above benchmark compared to $53 \%$ households in comparison areas $(p$-value $=.000)$ for having concrete tubewell platform without latrine within 12 steps (Table 2). About 7\% households in intervention areas stayed at benchmark (i.e. no stagnant water around the arsenic free tubewell) which was significantly lower than $17 \%$ households in comparison areas ( $p$-value $=.000)$.

\subsubsection{Hygienic Management of Drinking Water at Source and Point-of-use}

Steps to deem the hygienic management of drinking water were set as the use of arsenic free tubewell water, filtered or boiled surface water, safe collection, brick-built and crackles tubewell platform, and safe storage. Results indicated that a higher proportion of households scored above benchmark than that of comparison areas $(65 \%$ vs. $52 \%, p$-value $=0.000$ ) for having concrete tubewell platform and safe water storage at home after collection (Table 2). Conversely, at or below benchmark, the proportion of households in that range were higher in comparison areas than the intervention areas (at benchmark: 13\% vs. $21 \%, p$ value $=0.001$; below benchmark: $22 \%$ vs. $27 \%, p$ value $=0.121$ ). About $16 \%$ of households in intervention areas had safe drinking water source but water was not collected safely (Figure 2b).

\subsubsection{Condition of Hygienic Latrine Use}

A hygienic latrine generally characterized as containing a ring-slab with an active water seal is set as benchmark by the WASH programme. In intervention areas, a higher proportion of households scored benchmark in having hygienic latrines (ring-slab with water seal) compared to the comparison areas $(17 \%$ vs. $10 \%, p$-value=.002) (Table 2$)$. About $61 \%$ of households in intervention areas scored above benchmark which was significantly greater than comparison areas $(34 \%)(p$-value $=.000)$ in terms of clean and two-pit latrines. About $22 \%$ of households in intervention areas scored below benchmark because of following unhygienic sanitation practices (e.g. open defecation, latrine without ring-slab). The proportion (56\%, $p$-value $=.000)$ was significantly higher in comparison areas in using unhygienic latrines. In intervention areas, 78\% households used hygienic latrines (ring-slab with water seal) while the proportion was significantly higher than comparison areas $(44 \%, p$-value $=0.000)$. In intervention areas, $95 \%$ households used fixed latrine (i.e. latrine with ring-slab and/or water seal) which was significantly higher than those of comparison areas $(85 \%)(p$-value $=.000)$.

\subsubsection{Hand Washing}

Hand washing practice was measured by observing some proxy indicators such as the availability of water to wash hands in/near the latrine, soap/soap solution in bottle available in/near the latrine, and any other special arrangement made for hand washing. The households who scored above benchmark in intervention areas were more than twice as high as those in comparison areas (54\% vs. $23 \%, p$-value $=.000$ ) for using safe water in hand washing and having special hand washing station. In scoring below benchmark, the proportion of households in comparison areas was more than 1.5 times higher than that of intervention areas $(39 \%$ vs. $68 \%, p$-value $=.000)$ for the provision of available water in/near the latrine (Table 2). 
Table 2. Status of hygiene behaviors.

\begin{tabular}{|c|c|c|c|c|c|c|}
\hline \multirow{3}{*}{ Hygiene behavior } & \multicolumn{3}{|l|}{ Intervention } & \multicolumn{3}{|l|}{ Comparison } \\
\hline & $\begin{array}{l}\text { Above } \\
\text { benchmark }\end{array}$ & $\begin{array}{l}\text { At } \\
\text { benchmark }\end{array}$ & $\begin{array}{l}\text { Below } \\
\text { benchmark }\end{array}$ & $\begin{array}{l}\text { Above } \\
\text { benchmark }\end{array}$ & $\begin{array}{l}\text { At } \\
\text { benchmark }\end{array}$ & $\begin{array}{l}\text { Below } \\
\text { benchmark }\end{array}$ \\
\hline & Col 1 & Col 2 & Col 3 & Col 4 & Col 5 & Col 6 \\
\hline Safe and protected drinking water source & 69 & 7 & 24 & 53 & 17 & 30 \\
\hline$p$-value & \multicolumn{6}{|c|}{ Col 1 vs. Col 4 (0.000); Col 2 vs. Col 5 (0.000); Col 3 vs. Col 6 (0.033) } \\
\hline Hygienic management of drinking water & 65 & 13 & 22 & 52 & 21 & 27 \\
\hline p-value & \multicolumn{6}{|c|}{ Col 1 vs. Col 4 (0.000); Col 2 vs. Col 5 (0.001); Col 3 vs. Col 6 (0.121) } \\
\hline Condition of hygienic latrine & 61 & 17 & 22 & 34 & 10 & 56 \\
\hline$p$-value & \multicolumn{6}{|c|}{ Col 1 vs. Col 4 (0.000); Col 2 vs. Col 5 (0.002); Col 3 vs. Col $6(0.000)$} \\
\hline Hand washing provision after defecation & 54 & 7 & 39 & 23 & 9 & 68 \\
\hline$p$-value & \multicolumn{6}{|c|}{ Col 1 vs. Col 4 (0.000); Col 2 vs. Col 5 (0.282); Col 3 vs. Col $6(0.000)$} \\
\hline Total & 440 & & & 440 & & \\
\hline
\end{tabular}

A comparative status for each of the above hygiene behaviors are presented graphically in Figure 2.

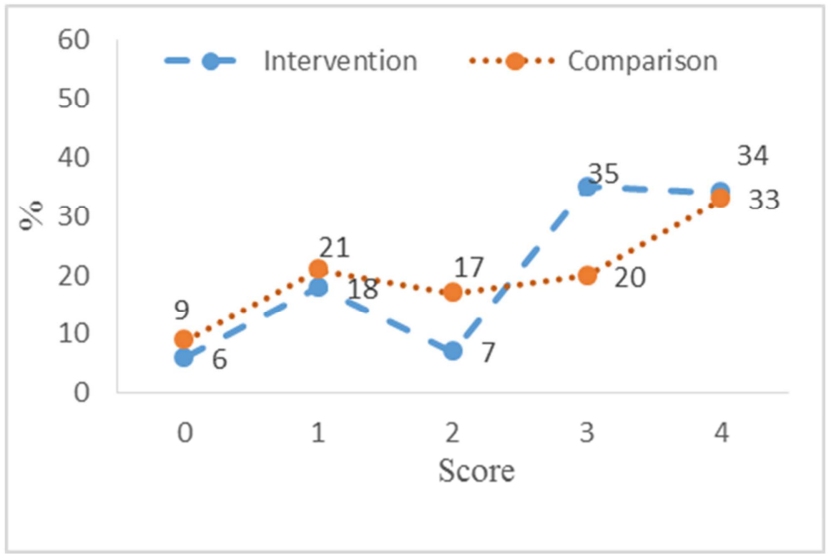

a. Safe and protected drinking water source.

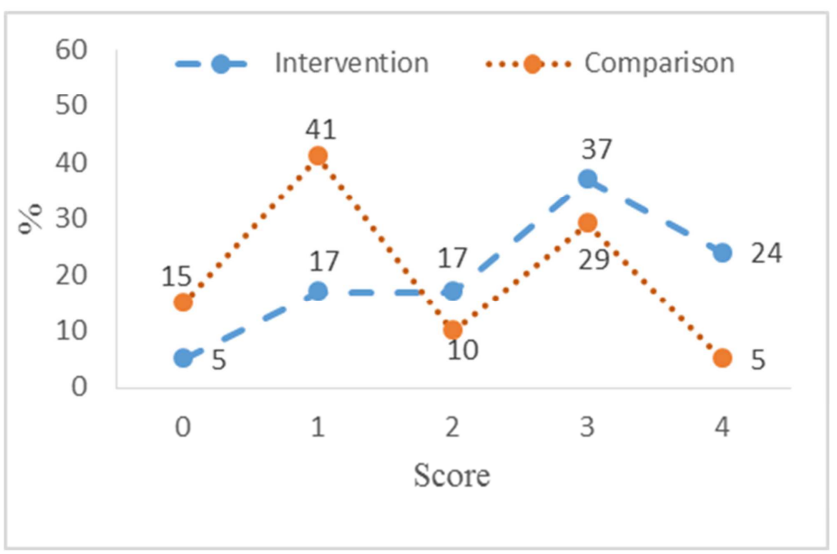

c. Condition of hygienic latrine.

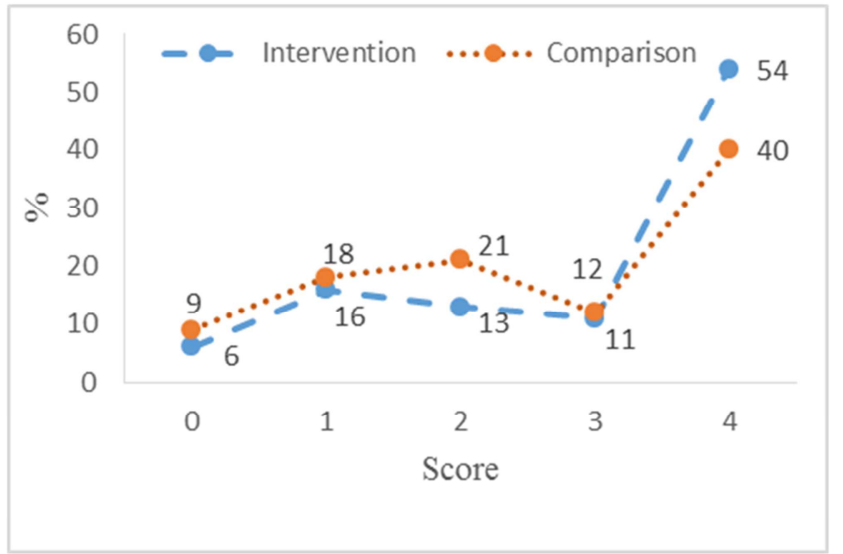

b. Hygienic management of drinking water

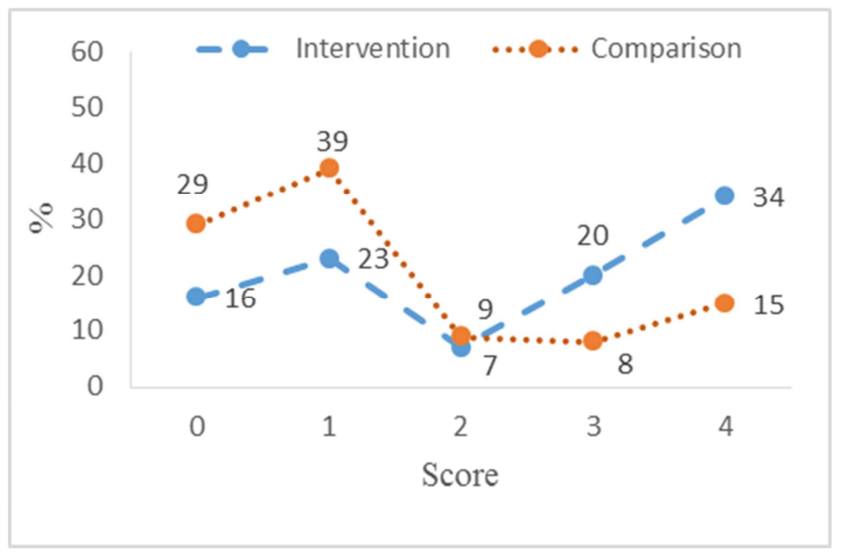

d. Hand washing provision after defecation.

Figure 2. Comparative status of scores for each behavior.

\subsubsection{Relative Results of Hygiene Practice}

The results show that those who had exposure to education were 1.4 times more likely to practice hygiene compared to those without schooling (95\% CI: 1.1-1.6) (Table 3). Households having access to radio and/or TV at home were 1.4 times more likely to practice hygiene compared to those with no access to media (95\% CI: 1.2-1.7). Also households affiliated with NGOs were 1.2 times (95\% CI: 1.1-1.4) more likely to practice hygiene compared to those who were not affiliated with NGOs. According to wealth quantile, the rich households were 1.5 times (95\% CI: 1.2-1.7) more likely to practice hygiene compared to the low wealth group. However, middle households were negatively associated with hygiene practice (IRR $0.6,95 \%$ CI: $0.4-0.8$ ) compared to the low wealth group. Dry region were 1.3 times (95\% CI: $1.1-1.5)$ more likely to practice hygiene compared to coastal region but flooded plain were negatively associated with hygiene practice (IRR 0.7, 95\% CI: 0.6-0.8) compared to coastal region. 
Table 3. Association between hygiene practice and its predictors.

\begin{tabular}{|c|c|c|c|c|c|c|}
\hline \multirow{2}{*}{ Indicators } & \multicolumn{6}{|l|}{ Adjusted } \\
\hline & IRR & Std. Err. & $\mathbf{z}$ & $\mathbf{P}>\mathbf{Z}$ & [95\% Conf.] & [Interval] \\
\hline \multicolumn{7}{|l|}{ Exposure to schools } \\
\hline Never schooling & 1 & & & & & \\
\hline \multirow{2}{*}{\multicolumn{7}{|c|}{ NGO membership }} \\
\hline & & & & & & \\
\hline No & 1 & & & & & \\
\hline Yes & 1.234114 & 0.085001 & 3.05 & 0.002 & 1.078271 & 1.412482 \\
\hline \multicolumn{7}{|l|}{ Media at home } \\
\hline No & 1 & & & & & \\
\hline Yes & 1.396271 & 0.119276 & 3.91 & 0 & 1.181017 & 1.650758 \\
\hline \multicolumn{7}{|l|}{ Wealth index } \\
\hline Low & 1 & & & & & \\
\hline Middle & 0.58272 & 0.10556 & -2.98 & 0.003 & 0.408568 & 0.831105 \\
\hline Rich & 1.451141 & 0.11054 & 4.89 & 0 & 1.249884 & 1.684805 \\
\hline \multicolumn{7}{|l|}{ Ecological zone } \\
\hline Coastal & 1 & & & & & \\
\hline Flood plain & 0.663058 & 0.054088 & -5.04 & 0 & 0.565088 & 0.778013 \\
\hline Barind (dry region) & 1.29669 & 0.105003 & 3.21 & 0.001 & 1.106389 & 1.519724 \\
\hline \multirow{2}{*}{ Indicators } & \multicolumn{6}{|c|}{ Unadjusted } \\
\hline & IRR & Std. Err. & $\mathbf{z}$ & $\mathbf{P}>\mathbf{Z}$ & [95\% Conf.] & [Interval] \\
\hline \multicolumn{7}{|l|}{ Exposure to schools } \\
\hline Never schooling & 1 & & & & & \\
\hline Ever Schooling & 1.586667 & 0.151016 & 4.85 & 0 & 1.316649 & 1.91206 \\
\hline \multicolumn{7}{|l|}{ NGO membership } \\
\hline No & 1 & & & & & \\
\hline Yes & 1.229167 & 0.095527 & 2.65 & 0.008 & 1.055499 & 1.431408 \\
\hline \multicolumn{7}{|l|}{ Media at home } \\
\hline No & 1 & & & & & \\
\hline Yes & 1.655827 & 0.151952 & 5.5 & 0 & 1.383254 & 1.982111 \\
\hline \multicolumn{7}{|l|}{ Wealth index } \\
\hline Low & 1 & & & & & \\
\hline Middle & 0.486799 & 0.097914 & -3.58 & 0 & 0.328201 & 0.722035 \\
\hline Rich & 1.307095 & 0.102489 & 3.42 & 0.001 & 1.120894 & 1.524227 \\
\hline \multicolumn{7}{|l|}{ Ecological zone } \\
\hline Coastal & 1 & & & & & \\
\hline Flood plain & 0.692771 & 0.062972 & -4.04 & 0 & 0.579718 & 0.827872 \\
\hline Barind (dry region) & 1.192771 & 0.095279 & 2.21 & 0.027 & 1.019912 & 1.394927 \\
\hline
\end{tabular}

\section{Discussion}

Behavior change remained at the heart of the BRAC WASH program. The present study measured water, sanitation and hygiene indicators at a scale in order to figure out the quality of practice at household level. Scaling principles of QIS ladder has been developed from no condition ( 0 score), through the primary to the secondary and tertiary characteristics towards improved behavior i.e. starting from the very basic to the advanced level of behavior change. The strength of this method is that each parameter or set of scores of the system is explored with detailed information collected qualitatively at first and quantified afterwards. The scenarios defined within the system such as "Benchmark" (i.e. presence of at least two basic characteristics is expected by the program), "Below benchmark" and "Above benchmark" entail the scope of improvement in hygiene behavior. The findings obtained through this analysis show the status and quality of WASH practice at household level in intervention and comparison upazilas.

The households were motivated about the use of safe and protected drinking water source characterized by arsenic free tubewell water, filtered or boiled surface water, no stagnant water around the tubewell, brick-built and crackles tubewell platform and no latrine in 12 steps of tubewell. The use of safe and protected drinking water source has been found significantly higher in intervention areas than the comparison areas. The probable reason behind such improvement of using safe drinking water is the thrust on improving hygiene behavior and health of the poorest of the poor has always been remained at the core of the WASH programme. As reported in Hossain et al. [14], majority of households (89\%) preferred and used tubewell water which was arsenic free and this happened because of increased awareness among the users. Taha et al. [15] identified the significant use of tubewell water for domestic purposes among the mothers in treatment areas than comparison areas. However, water safety remains at high risk if latrines are installed within the recommended 12 steps of tubewell. UNICEF guidelines adapted from WHO instructions included installing tubewell at a safe distance from latrines, and ensuring a tubewell platform without cracks preventing dirty water from entering into the aquifer. The presence of a latrine within $30 \mathrm{~m}$ was not reported as a statistically significant risk factor. However, 
sanitary inspection of tubewell developed by UNICEF Bangladesh considered the presence of latrine within $10 \mathrm{~m}$ of the tubewell as potential risk factor [16].

Rahman et al. found a higher concentration of fecal coliform in the tubewell water close to the latrine than the farther one. To avoid the possibility of fecal contamination, groundwater flow direction and a safe distance ( $>10$ feet) between the tubewell and latrine has been recommended by some environmental researchers [17]. In the present study, no significant difference $(p$-value $=0.214)$ was found in installing latrines more than 12 steps of tubewell among the households between intervention and comparison areas. This implies that households are probably unaware about the risks of fecal contamination of drinking water or they may install the tubewell close to the latrine considering water availability for personal and latrine cleanliness.

In intervention areas households are motivated to maintain hygienic management of drinking water from source to pointof-use through safe collection by using and covering clean pot as well as safe storage of water at a dry and elevated place inside the home. Consequently, a higher proportion of households was found managing drinking water safely. However, increased hygienic management of drinking water without testing microbial water quality may be considered as a crude way of measuring water safety. Study conducted on microbial status of households' drinking water at source and point of use depicted that $57.5 \%$ of drinking water sources were found safe $(0 \mathrm{FC} / 100 \mathrm{ml})$ i.e. the source was free from fecal contamination. However, only $7.5 \%$ of water samples collected from storage pots at home were found safe implying that a large proportion of households' drinking water $(57.5 \%$ vs. $7.5 \%$; a difference of $50 \%$ points) became contaminated in-between stages [18]. It is reported that safe storage of drinking water reduces fecal contamination. However, bacterial contamination was found higher after testing household's stored water [19].

Hygienic latrine with ring-slab and an active water seal is set as the benchmark by the BRAC WASH program. To break the contamination cycles, households are encouraged to keep the latrines clean so that no feces remained visible in pan, slab, water seal and walls. More households in the intervention areas used clean hygienic latrine than the comparison areas and the difference was statistically significant ( $p$-value $=.002$ ). If $16.8 \%$ latrines, which had no water seal, could have been changed into hygienic latrines by replacing water seal and added with $78 \%$ hygienic latrines, then the coverage of hygienic latrines in intervention areas would stand at about $95 \%$. Households in the water shortage areas have a tendency to break the water seal acting as a barrier towards increased sanitation coverage. A large amount of water is required to clean water seal, while carrying water is a difficult task. Thus they break the water seal to reduce work load of carrying water. Inadequate water supply causes poor sanitation and maintenance of personal hygiene affecting health of the populations [20].

Improved hand hygiene with available water and soap has been promoted in hand washing by the WASH programme. To measure hand washing behavior we checked on the spot the availability of soap and water. Reported hand washing behavior is not considered an effective measure, while observed behavior is often expensive, time consuming and often actual behavior is unseen due to the presence of the observer. Thus, spot check of availability of soap and water is a proxy indicator of measuring hand washing behavior which is more practical and inexpensive method of hand washing in resource poor context like Bangladesh. However a question was raised on the validity whether this method is associated with in the progress of hand washing behavior or reducing associated diseases [16]. The present study found that a good number of households could not reach benchmark since lack of availability of water and soap in or near the latrine. Cost, theft are some of the major factors acting as barriers towards soap availability in or near the latrine in low income communities $[21,9]$. To improve this condition, low cost soap solution in plastic bottle has been promoted by the BRAC WASH program. A study conducted in ICDDR, B depicted that the estimated cost of bar soap is higher than soap solution. Besides bar soap and soap solution last for the same duration [21].

Households in the lower strata of society with low socioeconomic status such as no schooling, no access to media, lowest in asset possessions are less likely to practice hygiene. Yusuf and Hossain reported that people's sanitation behavior is influenced by their culture and education [22]. A study by Akter et al. found a significant association between access to media (radio and/or TV) and use of hygienic latrine [6]. Similar with the current findings, Hadi and Nath explained that NGO's assistance helped change people's sanitation behavior by increasing their awareness and enhancing and augmenting their financial capacity [23]. However, the probability of hygienic latrine use was not manipulated by NGO membership as depicted in other findings which differed with our results. The households in middle wealth group were found negatively associated with the low wealth group. A complex mindset among them may have been an effect of not pursuing hygiene because the poor often did not prefer procurement of latrine on loan because of repayment hassle [9]. They often thought that they would get programme's hardware support at free of cost differing the programme's rule of supporting the poorest of the poor.

\section{Conclusions}

An improved status in hygiene behavior has been observed among the households in intervention areas than the comparison areas. Households mostly used arsenic safe drinking water except the few in intervention areas. However some of them did not follow the proper steps of hygienic management of drinking water. According to the findings, a certain proportion of households could not reach benchmark since lack of availability of water and soap in or near the latrine for hand washing after defecation. Awareness on unhygienic sanitation behaviors such as open defecation, latrine without ring-slab and/or water seal, etc. and relative distance between the latrine and tubewell are required for enabling environment, thus public health. 


\section{Author Details}

Research and Evaluation Division, BRAC Centre, 75 Mohakhali, Dhaka 1212, Bangladesh.

\section{Authors' Contributions}

TA contributed to the conception, study design, data collection, analysis, interpretation of data and writing the manuscript as the lead author. FTJ contributed in data collection and analysis. MR contributed in data analysis and writing. MR commented on the draft manuscript. Authors read and approved the final manuscript.

\section{Competing Interests}

The authors declare that they have no competing interests.

\section{Acknowledgements}

The Government of Royal Netherlands is acknowledged for funding the BRAC WASH program.

\section{References}

[1] UNO. The Sustainable Development Goals Report 2018. 2018. Available at: https://unstats.un.org/sdgs/files/report/2018/thesustainabledev elopmentgoalsreport2018.pdf.

[2] Bartram J, Cairncross S. Hygiene, sanitation and water: Forgotten foundations of health. PLoS Med. 2010; 7 (11): 1000367. doi: 10.1371/journal/pmed.1000367.

[3] WHO, UNICEF. Progress on sanitation and drinking water2013 update. 2013. Available at: http://www.wssinfo.org/fileadmin/user_upload/resources/JMP report2013.pdf.

[4] Mara D, Lane J, Scott B, Trouba D. Sanitation and health. PLoS Med. 2010; 7: 1-7.

[5] UNICEF. Progress on drinking water and sanitation. 2014. Available www.unicef.org/.../Progress_on_drinking_water_and_sanitati on_2014_upd.

[6] Akter T, Ali ARMM, Dey NC. Transition overtime in household latrine use in rural Bangladesh: a longitudinal cohort study. BMC Public Health. 2014; 14: 721.

[7] Rabbi SE, Dey NC. Exploring the gap between hand washing knowledge and practices in Bangladesh: a cross-sectional comparative study. BMC Public Health. 2013; 13: 89. http://www.biomedcentral.com/1471-2458/13/89 (accessed on 13 September 2013).

[8] Dey NC, Karim F, Rabbi SE. Use of tubewell water for different purposes at household level: safety practices in rural Bangladesh. In: achievements of BRAC water, sanitation and hygiene programme towards Millennium Development Goals and beyond. Dhaka: BRAC.

[9] Akter T, Ali ARMM. Factors influencing knowledge and practice of hygiene in Water, Sanitation and Hygiene (WASH) programme areas of Bangladesh Rural Advancement Committee. Rural Remote Health. 2014; 14: 2628. (Online).

[10] Hanchett S, Khan MH, Krieger L, Kullmann C. Sustainability of Sanitation in Rural Bangladesh, The future of water sanitation and hygiene: Innovation, adaptation and engagement in a changing world. Loughborough, UK: $35^{\text {th }}$ WEDC International Conference. 2011.

[11] Ruzicajacimovic, Ahmed M, Boston K. Programme performance monitoring: Report on QIS data analysis (WASH I). IRC, The Hague, the Netherlands. 2014.

[12] Diaz-Quijano FA: A simple method for estimating relative risk using logistic regression. BMC Med Res Methodol. 2012; 12: 14.

[13] Cummings P. Methods for estimating adjusted risk ratios. The Stata Journal. 2009; 9 (2): 175-196.

[14] Hossain M, Rahman SN, Bhattacharya P, Jacks G, Saha R and Rahman M. Sustainability of arsenic mitigation interventions - an evaluation of different alternative safe drinking water options provided in Matlab, an arsenic hot spot in Bangladesh. Front. Environ. Sci. 2015; 3: 30. doi: 10.3389/fenvs.2015.00030.

[15] Taha AZ, Sebai ZA, Shahidullah M, Hanif M, Ahmed HO. Assessment of water use and sanitation behavior of a rural area in Bangladesh. Arch Environ Health. 2000; 55 (1): 51-7.

[16] Luby SP, Gupta SK, Sheikh MA, Johnston RB, Ram PK, Islam MS. Tubewell water quality and predictors of contamination in three flood-prone areas in Bangladesh. Journal of Applied Microbiology. 2008; 105: 1002-1008.

[17] Rahman SH, Fakhruddin ANM, Uddin MJ, Zaman MS, Talukder A, Adyel TM, et al. Water quality of shallow tubewells as affected by sanitary latrines and groundwater flow. Journal of Bangladesh Academy of Sciences. 2013; 37 (2): 231-243.

[18] Akter T, Jhohura FT, Chowdhury TR, Akter F, Mistry SK, Rahman M. Assessment of drinking water quality based on chemical and microbiological parameters in rural Bangladesh. Trop Med Int Health. 2015; 20 (Suppl. I): 1-147.

[19] Davis J, Pickering AJ, Rogers K, Mamuya S, Boehm AB. The effects of informational interventions on household water management, hygiene behaviors, stored drinking water quality and hand contamination in peri-urban Tanzania. Am. J. Trop. Med. Hyg. 2011; 84 (2): 184-191.

[20] Hunter PR, MacDonald AM, Carter RC. Water supply and health. Plos Medicine. 2010; Vol 7 (11).

[21] Amin N, Pickering AJ, Ram PK, Unicomb L, Najnin N, Homaira N, et al. Microbiological Evaluation of the Efficacy of Soapy Water to Clean Hands: A Randomized, NonInferiority Field Trial. Am. J. Trop. Med. Hyg. 2014; 91 (2): 415-423.

[22] Yusuf M, Hussain AMZ. Sanitation in rural communities in Bangladesh. Bull WHO. 1990; 68: 619-624.

[23] Hadi A, Nath SR. Raising sanitary latrine use in rural Bangladesh: can BRAC play any role? Watch report no. 22. Dhaka, Bangladesh: BRAC. 1996. (2): 184-191. 